\title{
Anethumgraveolens and Apiumgraveolens leaf-extract and their antifungal effects on pathogenic Candida species: In vitro study
}

\section{Abstract}

Background and objective: The constant increase of Candida infection and unstopping emergence of drug resistant Candida species is a major concern. Natural medicinal products particularly those of edible plant could be a safe and effective alternative to synthetic substances. Considering their anti-microbial contents, the leave extracts of Anethemgraveolens and Apiumgraveolens have been investigated for their effects against Candida species.

Methods: Fresh leaves of Anethem and Apium were collected from Erbil province in Iraq. The leaves were dried then after grinding the ethanol extract was prepared. The radical scavenging activity of extracts was measured via DPPH inhibition activity method. Anti-Candida effect was assessed against C. albicans, C. glabrata, C. krusei, C. tropicalis, C. tamatta, C. parapsiosis, and C. guilliermondii. Standard antifungal drugs were used as control including Nystatin, Clotrimazole, Fluconazole, Ketoconazole, and Miconazole.

Results: The highest radical scavenging activity of both extracts was found at $0.2 \mathrm{mg} / \mathrm{mL}$. Both extracts did not affect the growth inhibition of C. krusei, C. tropicalis, and C. tamatta. However, they were significantly effective to the extent of other antifungal drugs against the growth of other Candida species including C. albicans, C. glabrata, C. guillermondii, and C. parapsiosis.

Conclusion: The findings of this study suggest that both Apium and Anethem which are widespread vegetable and could have similar anti-Candia effects which can be a great alternative to the commonly used antifungal drugs.

Keywords: Anethemgraveolens; Apiumgraveolens; Candida; Anti-fungal drugs.

\section{Introduction}

Candida infections and associated mortality occur in a remarkably increasing pattern over the last years mainly due to the rise in immunocompromised population undesirable toxicity and side effects, limitations in currently available anti-fungal agents and a growing number of resistant Candida species. ${ }^{1}$ It has been roughly estimated that nearly 300,000 people are infected with invasive candidiasis globally which claims about 50,000 lives annually. ${ }^{2}$ Recent surgery, the presence of central vascular catheters and broad spectrum antibiotic administration are considered the main risk factors for candidiasis. ${ }^{3}$ During the past decade the management of candidiasis has seen fundamental changes. The currently applied four classes of antifungal agents against Candida infections are echinocandins, polyenes, fluoropyrimidines, and azoles. ${ }^{4}$ Nevertheless, substantial clinical challenges are posed to the treatment of candidiasis due to the side effects, toxicity and emergence of resistant strains. Species of Candida differ in virulence and epidemiology. C. albicans, C. tropicalis, and C. glabratadisplay higher virulence than $C$. parapsilosis and C. krusei. However, despite its low virulence, C. parapsilosis creates huge problems in certain clinical settings due to its ability

* Department of Microbiology, College of Medicine, Hawler Medical University, Erbil, I raq.

** Department of Biology, College of Science, Salahaddin University, Erbil, I raq. 
to colonize human skin and propensity to adhere to medical devices which facilitates nosocomial outbreaks. ${ }^{5}$ The emergence of resistant Candida species and their constant changes in epidemiology merit vigilance. The management of candidiasis has entered a new era in which new types of treatment are likely to provide better outcomes for patients. Such novel anti-fungal agents necessarily should possess more effectiveness and less toxicity than available synthetic drugs. ${ }^{6}$ Essential oils, as natural medicinal products, have anti-fungal and anti-oxidant activities. ${ }^{7}$ The genus Anethumgraveolens (Dill) in Apiaceae family is a traditional Asian medicine that native to South Eastern Europe and South Western Asia. ${ }^{8}$ Dill has long been used for seasoning and in food industries. Among active components of Anethumgraveolens are essential oils, phenolic compounds, and flavonoid which propose a variety of pharmacological properties to the plant including anti-hypercholesterolic ${ }^{9}$ and antibiotic effects ${ }^{10}$. Similarly, Apiumgraveolenes (Celery) in the same family of Apiaceae, is mainly used as spice has broad pharmaceutical applications. Leaves root and stem of celery have constituents such as flavones, phenolic compounds, flavonols, furanocoumarins, and phthalide derivatives. ${ }^{11}$ Studies suggest its application in the prevention of cardiovascular diseases due to anti-coagulation $^{12}$ and anti-inflammatory activities. ${ }^{13}$ The current study aimed to assess the anti-candida activity of Anethumgraveolens and Apiumgraveolens in view of their wide use in the daily meal and their valuable chemical and antibiotic constituents.

\section{Methods}

\section{Sample collection and preparation}

Fresh leaves of Anethumgraveolenes and Apiumgraveolenes were collected in HanaraeSarw region in Erbil governorate of Iraq and stored to dry at room temperature. Taxonomic identification was done in Crop field department of the College of Agriculture at Salahaddin University. The dried leaves were crushed to form powder then sieved through different meshes and stored at $4^{\circ} \mathrm{C}$ until extraction. Extraction was done by dissolving $5 \mathrm{~g}$ of powder in $50 \mathrm{ml}$ of $95 \%$ ethanol at $45^{\circ} \mathrm{C}$ for 30 minutes in a beaker with the magnetic stirrer. The solid residues were removed via filtration and the eluted liquid heated to dry at $37^{\circ} \mathrm{C}$ in a rotary vacuum evaporator. $^{14}$ The yield amount was measured as the ratio of the dried weight of extract on the dried weight of leaves in percent. Total condensed tannin was determined by adding $0.01 \mathrm{~g}$ of extracts and mimosa tannin into $10 \mathrm{~mL}$ of extraction solution which is made of a mixture of $\mathrm{Fe}_{2} \mathrm{SO}_{4}(0.05 \mathrm{~g}), \quad \mathrm{N}$-butanol $(95 \mathrm{~mL})$ and $35 \% \mathrm{HCL}(5 \mathrm{~mL})$. The solution was heated in a water bath at $45^{\circ} \mathrm{C}$ for $1 \mathrm{~h}$ then the absorbance was measured at $580 \mathrm{~nm}^{15}$ The free radical scavenging activity of extracts was measured by a slight modification of DPPH assay in which 1,1-diphenyl-2-picrylhydrazyl (DPPH) absorption level decreases at 517 $\mathrm{nm}$ with reduction of radical species. Briefly, $1 \mathrm{~mL}$ of $0.1 \mathrm{mM}$ DPPH was mixed separately with $0.1,0.2$ and $0.3 \mathrm{ml}$ of sample solutions. The mixture was shaken vigorously and placed out of light at room temperature for 30 minutes. The absorbance was measured at $517 \mathrm{~nm}$. As reference Butylated hydroxytoluene $(\mathrm{BHT})$ was used and the radical scavenging activity was expressed as the inhibition percentage of free radicals in the sample and calculated with the following equation. ${ }^{16}$

InhtbttonofDPPHactivti $=\frac{A-B}{d} \times 100$

Where $\mathbf{A}$ is the absorbance of DPPH and is the absorbance with sample and BHT.

\section{Antimicrobial activity}

\section{Candida inoculum:}

Seven Candidaspp used in this study were collected from vaginal samples of patients attended the gynecology and obstetrics department of Maternity Teaching Hospital 
in Erbil city. The identification of Candida species was done using VITEK® 22 YST ID Card (Biomerioux, Marcy-l'Étoile, France). The isolated Candida spp were inoculated on Sabouraud Dextrose Agar (SDA) for $24 \mathrm{~h}$ at $37^{\circ} \mathrm{C} .{ }^{17}$ One colony was transferred into $200 \mu \mathrm{L}$ sterile distilled water then the suspension was diluted 1:10 in sterile distilled water. A $20 \mu \mathrm{L}$ aliquot per test was delivered onto filter paper disc impregnated with extract. Accordingly, three control replicates were made by inoculating $20 \mu \mathrm{L}$ of the same aliquot on a pure SDA agar to which the colony enumeration was performed the next day. The counts were $2.5 \pm 0.2 \times 10^{5}$ colony/ $\mathrm{mL}{ }^{18}$

\section{Disc diffusion (DD)}

Antimicrobial activity was carried out using disc diffusion method (i.e., CLSI technique). ${ }^{19}$ Briefly, filter paper discs (6mm in diameter) were impregnated with $50 \mu \mathrm{l}$ of plant extracts and allowed to dry. The discs were placed on SDA inoculated with $20 \mu \mathrm{L}$ of Candida suspension and incubated at $37^{\circ} \mathrm{C}$ for $48 \mathrm{~h}$. Antifungal discs were made and applied in the same way and used as controls. Antimicrobial activities were evaluated by measuring the inhibition zones around the implemented discs. All tests were performed with six replicates.

Minimum Inhibitory Concentration (MIC) The MICs of extracts and antifungal agents for each isolate were determined by making five ten-fold serial dilutions of agents with distilled water. The Candida inoculum was prepared by suspending five colonies of at least $1 \mathrm{~mm}$ diameter in

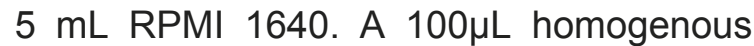
Candida suspension was transferred onto SDA to define CFU/mL. The Candida suspensions were adjusted in $50 \mu \mathrm{L}$ per well of RPMI 1640 to $0.5 \times 10^{3}$ to $2.5 \times$ $10^{3} \mathrm{CFU} / \mathrm{mL}$ in 96 well microdilution plates. From each dilution of extract or antifungal agent, $50 \mu \mathrm{L}$ was added per well of Candida dilutions then incubated at $37^{\circ} \mathrm{C}$ for 24 hours. Theanti-fungal MIC endpoint was defined as the lowest concentration that inhibited $50 \%$ of fungal growth compared to the growth of the growth control (no anti-fungal suspension). ${ }^{18}$

Data analysis

Data was analyzed by GraphPad Prism v6. A $P$ value of 0.05 was considered as statistically significant. Student t-test was applied to find out the statistically significant differences between studied groups. In addition, Spearman's Ranked correlation was done to define the associations attributed to the variables. To attain the reproducibility of the test and achieve biologically meaningful procedure, each experiment was performed upon 6 biological replicates.

\section{Results}

Yield and condensation of root extracts

The percentage of extraction was measured for $50 \mathrm{mg}-100 \mathrm{mg}$ yield from Apiumgraveolens and $75 \mathrm{mg}-125 \mathrm{mg}$ yield Anethum graveolens out of initial dried leaves (Figure 1A). Also, their total condensed tannin is presented in (Figure 1B).

The radical scavenging activity of extracts

The radical scavenging activity of the Apiumgraveolens and Anethum graveolens extracts with various extraction methods and BHT (Figure 2)showed a statistically significant difference between $0.1 \mathrm{~mL}$ and $0.2 \mathrm{~mL}$ of extracts as well as between 0.2 $\mathrm{mL}$ and $0.3 \mathrm{~mL}$ of extract. The statistical difference indicates the best scavenging activity of extracts at $0.2 \mathrm{ml}$.

Anti-Candida Activity of the extracts The effect of Root Extracts in killing different Candida species was measured via paper disc and MIC on SDA measured in millimeters (Table 1). There was a correlation between the anti-candida effects of Paper Disc Diffusion and MIC; when both methods were applied against various Candida species.

\section{Spearman's Ranked Correlation $=\mathbf{+ 0 . 6}$} The correlation coefficient between Paper disc diffusion and MIC applied for both extracts in all Candida species. 
Table 1: Inhibition zones using Paper Disc diffusion and minimum inhibitory concentration (MIC) of the extracts against Candida spp. Two methods have shown a relatively good correlation $(R=0.6)$ in their anti-candida effects.

\begin{tabular}{|c|c|c|c|c|c|c|c|c|c|}
\hline & & & $\begin{array}{c}\text { C. } \\
\text { albicans }\end{array}$ & $\begin{array}{c}\text { C. } \\
\text { galbrata }\end{array}$ & $\begin{array}{c}\text { C. } \\
\text { krusei }\end{array}$ & $\begin{array}{c}\text { C. } \\
\text { tropicalis }\end{array}$ & $\begin{array}{c}\text { C. } \\
\text { famatta }\end{array}$ & $\begin{array}{c}\text { C. } \\
\text { parapsiosis }\end{array}$ & $\begin{array}{c}\text { C. } \\
\text { guilliermondii }\end{array}$ \\
\hline \multirow[t]{2}{*}{$\begin{array}{l}\text { Apium } \\
\text { graveolens }\end{array}$} & $\begin{array}{l}\text { Paper } \\
\text { disc } \\
\text { diffusion } \\
(\mathrm{mm})\end{array}$ & $\begin{array}{l}\text { Mean } \\
\pm S D\end{array}$ & $16 \pm 0.43$ & $8.1 \pm 0.5$ & - & - & - & $10.1 \pm 2$ & $15 \pm 0.37$ \\
\hline & $\begin{array}{l}\text { MIC } \\
(\mathrm{mg} / \mathrm{mL})\end{array}$ & $\begin{array}{l}\text { Mean } \\
\pm S D\end{array}$ & $15.6 \pm 0.57$ & $125 \pm 1.0$ & - & - & - & $62.5 \pm 0.5$ & $15.6 \pm 1.15$ \\
\hline \multirow[t]{2}{*}{$\begin{array}{l}\text { Anethum } \\
\text { graveolens }\end{array}$} & $\begin{array}{l}\text { Paper } \\
\text { disc } \\
\text { diffusion } \\
(\mathrm{mm})\end{array}$ & $\begin{array}{l}\text { Mean } \\
\pm S D\end{array}$ & $15 \pm 0.53$ & $9 \pm 0.4$ & - & - & - & $15 \pm 1.0$ & $15.3 \pm 0.59$ \\
\hline & $\begin{array}{l}\text { MIC } \\
(\mathrm{mg} / \mathrm{mL})\end{array}$ & $\begin{array}{l}\text { Mean } \\
\pm S D\end{array}$ & $15.6 \pm 0.33$ & $62.5 \pm 1.6$ & - & - & - & $15.6 \pm 0.5$ & $15.6 \pm 2.15$ \\
\hline
\end{tabular}
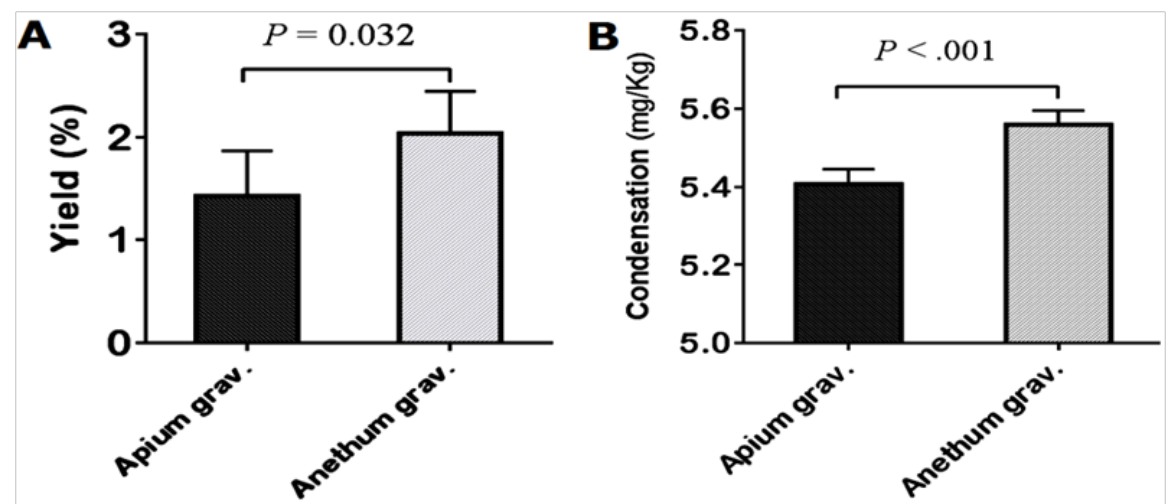

Figure 1: The leaf extracts from5g Apiumgraveolens dried leaves had $50 \mathrm{mg}-100 \mathrm{mg}$ yield and5g Anethumgraveolens dried leaves gave $75 \mathrm{mg}-125 \mathrm{mg}$ yield. The efficiency of extraction was measured as A) yield percentage and B) the condensation in $\mathrm{mg} / \mathrm{Kg}$ for both species. Error bars represent SD for 6 replicates.
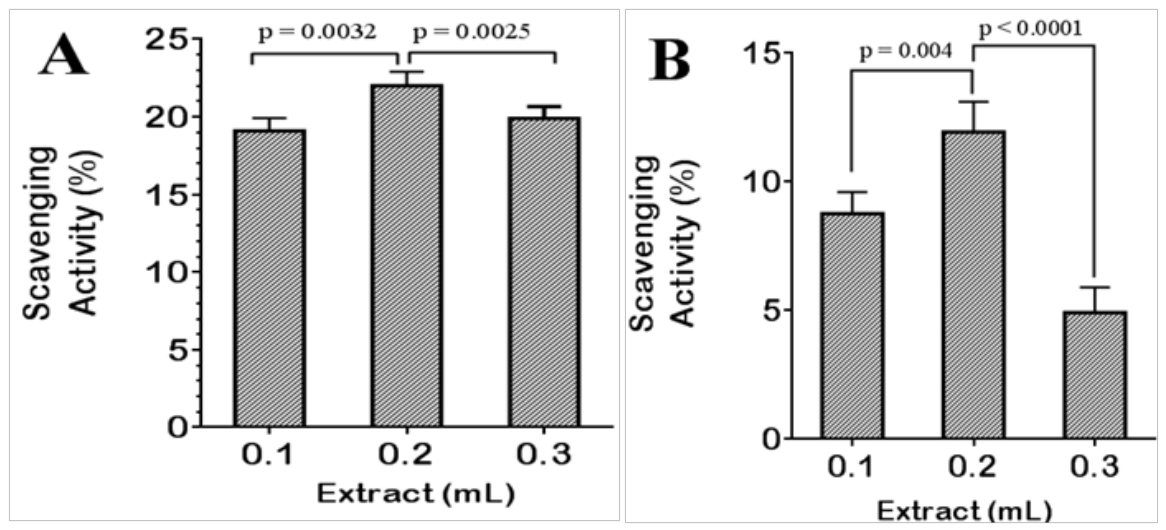

Figure 2: DPPH scavenging activities of extracts of A) Apiumgraveolens and B) Anethumgraveolens. Paired t-test was performed to determine the statistical differences between two extract volumes. Error bars represent SD. 
Anti-Candida activity of extracts compared to synthetic antibiotics

As comparison the target Candida species were challenged with common anti-fungal agents. Figure 3 displays the killing efficiency of extracts and synthetic drugs.

\section{Discussion}

Microbial inhibitors are widely available in many edible plants. In view of that, we have investigated the antiCandida effects of Apiumgraveolens and Anethemgravelones both of which are commonly contributed in The Middle Eastern and Mediterranean cuisine.
Because the leaves of these plants are the main part for consumption and the anti-microbial effects have been shown to be higher for leave extracts of these plants compared to their seeds and root, the study was based on leave extracts. The most commonly applied extraction method was used to get the maximum yield with the highest condensation (Figure 1). Nevertheless, the method proved more efficiency in yield and condensation for Anethem than Apium. Such a difference seems to be attributed to the leave structure and contents. ${ }^{20}$ Despite their difference in yield and condensation the
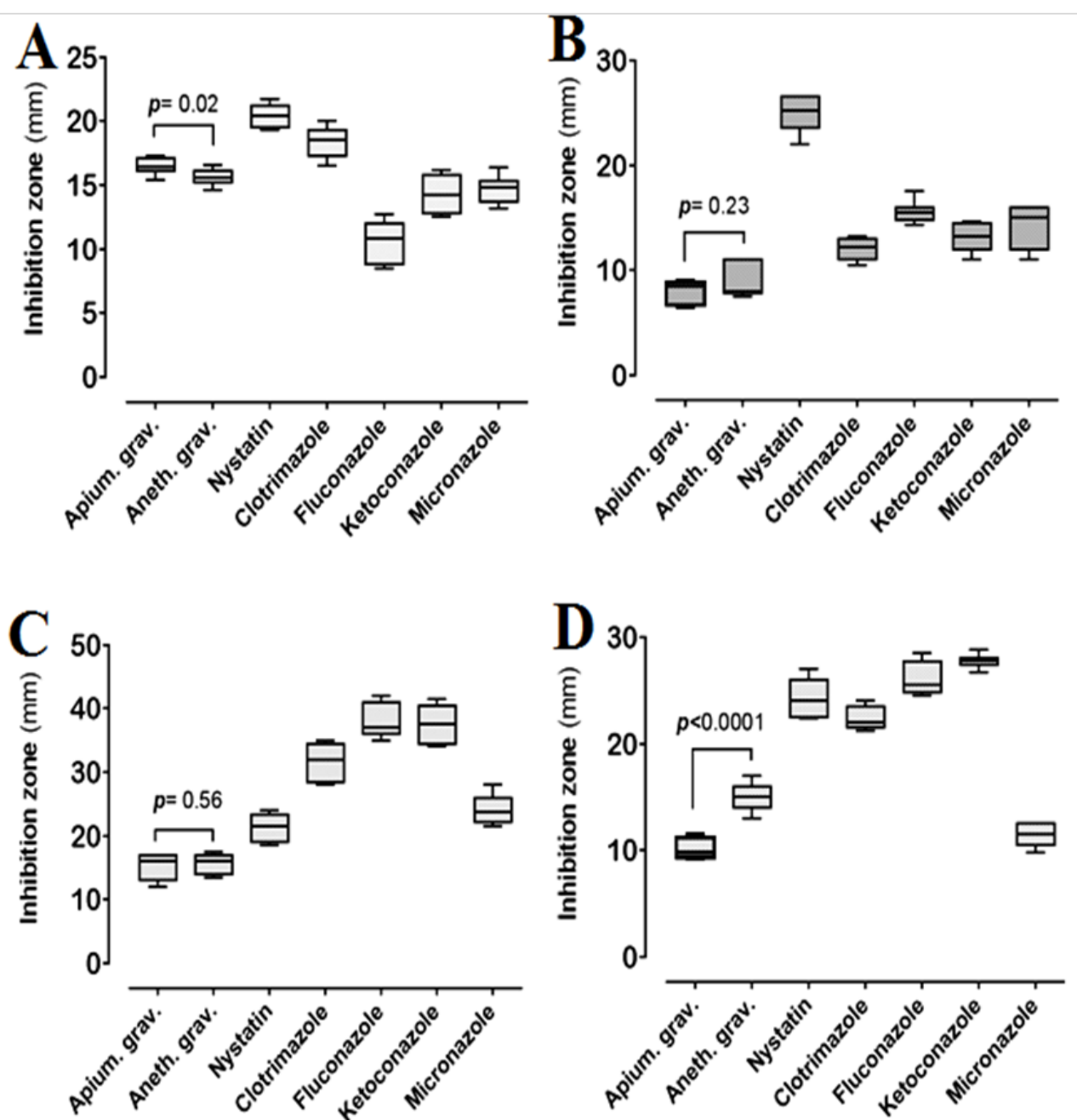

Figure 3: Inhibition zones of extracts and synthetic drugs against $C$. albicans (A), C. galbrata (B), C. gulliermondii (C) and C. parapsiosis (D). The anti-candia effects of Apium and Anethem extracts were statistically compared using t-test Error Bars represent min and max and median from six replicates. 
scavenging activity of Apium and Anethem was found to be similar (Figure 2). In this regard, the optimal concentration with maximum scavenging ability was $0.2 \mathrm{~mL}$. The increased concentration led to a relatively lower scavenging activity of extracts. This was in agreement with previous studies done by Enayatet al. ${ }^{21}$ With this result, the leave extracts exhibited antioxidant potential as supported by Sonboli et $a{ }^{2}{ }^{22}$ The mechanism of radical scavenging activity of Apiumgraveolens $L$. and Anethum graveolens could be attributed to the presence of polyphenolic compounds. ${ }^{23}$ It has already been exhibited that the polyphenolic compounds are responsible for radical scavenging activity due to their hydrogen atom donation to active free radicals. ${ }^{24}$ Phenols are very important plant constituents because of their scavenging ${ }^{25}$ or anti-oxidative abilities. ${ }^{26}$ In our experiment, the antiCandida effects of extracts were assessed via disc diffusion method. The extracts of Apium and Anethem were found to be effective in growth inhibition of C. albicans, C. glabrata, C. parapsiosis and C. guilliermondii but unable to stop the growth of C. krusei, C. tropicalis and C. tamatta (Table 1). Measuring the MIC showed very similar quantities for both extracts as minimal inhibition with a good correlation pattern $(r=0.6)$. Interestingly, the anti-Candida activity of extracts was observed against species that are common human pathogens. ${ }^{27}$ Such variation in anti-Candida activity of plant required further investigation through which several factors need to be studied. In view of that, the mechanism of the vulnerability of killed Candida species as well as the strategies by which resistant species could survive under the effect of extracts need to be elucidated. The anti-Candida activity of extracts assessed on four Candida species through comparison with a standard antifungal medicine. The efficiency for the growth inhibition of $C$. albicans by the extract of Apium was very similar but statistically higher compared to Anethem
(Figure 3A). This is in agreement with the similar studies including a study on leave extracts of Eucalyptus ${ }^{28}$ and crude plant extract. ${ }^{29}$ Nevertheless, their effects were slightly lower than Nystatin and Clotrimazole which is in agreement with a study done by Sehal using Calotropisprocera extracts against C. albicans. ${ }^{30} \mathrm{~A}$ very similar efficiency of Apium and Anethem extracts was observed against $C$. glabrata which was very close to the effect of other antiCandida drugs except Nystatin (Figure 3B). The considerably higher effect of Nystatin indicates for the fact that it is a broad spectrum anti-Candida medicine. Although there was statistically no significant difference between Apium and Anethem extracts against $C$. gullimondii, the effect was relatively lower than all anti-Candida drugs (Figure $3 \mathrm{C}$ ). The prominent effect of Fluconazole in this regards is in accordance with the findings of an in vivo study on oral candidiasis in which there was greater removal of Candida species by Fluconazole than Nystatin. ${ }^{31}$ The most noticeable killing effect difference between extracts was observed in their activity against $C$. parapsiosis (Figure 3D). This might be due to their differences in antimicrobial composition ${ }^{6}$. In this regard, two anti-fungal agents namely D-limonene and D-Carvone are more abundant in Anethem compared to Apium. ${ }^{20}$

\section{Conclusion}

The findings of this study promote the view of using natural products in the treatment of human candidiasis. Moreover, the beneficial effects of such extracts in regulating blood sugar and cholesterol $^{8}$ in addition to their relatively lower side effects favor the point that they might be a good alternative to synthesized drugs.

\section{Competing interests}

The authors declare that they have no competing interests. 


\section{References}

1. Teodoro GR, Ellepola K, Seneviratne CJ, Koga-ito CY. Potential Use of Phenolic Acids as AntiCandida Agents: A Review. Front Microbiol 2015; 6:1420.

2. Arendrup MC. Epidemiology of invasive candidiasis. Curr Opin Crit Care 2010; 16(5):44552.

3. Kullberg BJ, Arendrup MC. Invasive Candidiasis. N Engl J Med 2015; 373(15):1445-56.

4. Vikrant P, Priya J, Nirichan KB. Plants with anti-Candida activity and their mechanism of action: a review. J Environ Res Dev 2015; 9(04):1189-96.

5. Vaz C, Sampaio P, Clemons K V., Huang YC, Stevens DA, Pais C. Microsatellite multilocus genotyping clarifies the relationship of Candida parapsilosis strains involved in a neonatal intensive care unit outbreak. Diagn Microbiol Infect Dis 2011; 71(2):159-62.

6. Bakkali F, Averbeck S, Averbeck D, Idaomar M. Biological effects of essential oils--a review. Food Chem Toxicol 2008; 46(2):446-75.

7. Arash A, Mohammad MZ, Jamal MS, Mohammad TA, Azam A. Effects of the aqueous extract of anethum graveolens leaves on seizure induced by pentylenetetrazole in mice. Malays J Med Sci 2013; 20(4):23-30.

8. Yazdanparast R, Alavi M. Antihyperlipidaemic and antihypercholesterolaemic effects of Anethum graveolens leaves after the removal of furocoumarins. Cytobios 2001; 105(410):185-91.

9. Kaur GJ, Arora DS. Antibacterial and phytochemical screening of Anethum graveolens, Foeniculum vulgare and Trachyspermum ammi. BMC Complement Altern Med 2009; 9:30.

10. Ovodova RG, Golovchenko VV, Popov SV, Popova GY, Paderin NM, Shashkov AS, et al. Chemical composition and anti-inflammatory activity of pectic polysaccharide isolated from celery stalks. Food Chem 2009; 114(2):610-5.

11. Sowbhagya HB, Srinivas $P$, Krishnamurthy $N$. Effect of enzymes on extraction of volatiles from celery seeds. Food Chem 2010; 120(1):230-4.

12. Al-Hindawi MK, Al-Deen IHS, Nabi MHA, Ismail MA. Anti-inflammatory activity of some Iraqi plants using intact rats. J Ethnopharmacol 1989; 26(2):163-8.

13. Laghari $A Q$, Memon $S$, Nelofar $A$, Laghari $A H$. Extraction, identification and antioxidative properties of the flavonoid-rich fractions from leaves and flowers of Cassia angustifolia. Am J Anal Chem 2011; 2(8):871-8.

14. Makkar HPS, Becker K, Abel H, Szegletti C. Degradation of condensed tannins by rumen microbes exposed to quebracho tannins (QT) in rumen simulation technique (RUSITEC) and effects of QT on fermentative processes in the RUSITEC. J Sci Food Agric 1995; 69(4):495500.
15. Gülçin I, Oktay M, Kireçci E, Küfrevioğlu ÖI. Screening of antioxidant and antimicrobial activities of anise (Pimpinella anisum L.) seed extracts. Food Chem 2003; 83(3):371-82.

16. May JL, King A, Warren CA. Fluconazole disc diffusion testing for the routine laboratory. J Antimicrob Chemother 1997; 40(4):511-6.

17. Cuenca-estrella M, Rodri JL, Mellado E, Di TM. Standardization of antifungal susceptibility variables for a semiautomated methodology. J Clin Microbiol 2001; 39(7):2513-7.

18. Singh V, Bala M, Kakran M, Ramesh V. Comparative assessment of CDS, CLSI disc diffusion and Etest techniques for antimicrobial susceptibility testing of Neisseria gonorrhoeae: A 6-year study. BMJ 2012; 2(4):e000969.

19. Al-Snafi AE. The Pharmacology of Apium graveolens - A Review. IJPRS 2014; 3(I-1):6717.

20. Enayat S, Banerjee S. Comparative antioxidant activity of extracts from leaves, bark and catkins of Salix aegyptiaca sp. Food Chem 2009; 116(1):23-8.

21. Sonboli A, Mojarrad M, Ebrahimi SN, Enayat S. Free radical scavenging activity and total phenolic content of methanolic extracts from male inflorescence of Salix aegyptiaca grown in Iran. Iran J Pharm Res 2010; 9(3):293-6.

22. Al-Snafi AE. The pharmacological importance of anethum graveolens. A review. IJPRS 2014; $6(4): 13-5$.

23. Xie B, Shi H, Chen $Q$, Ho CT. Antioxidant properties of fractions and polyphenol constituents from green, oolong and black teas. Proc Natl Sci Counc Repub China Part B Life Sci 1993; 17(2):77-84.

24. Hatano T, Yasuhara T, Fukuda T, Noro T, Okuda T. Phenolic constituents of licorice. II. Structures of licopyranocoumarin, licoarylcoumarin and glisoflavone, and inhibitory effects of licorice phenolics on xanthine oxidase. Chem Pharm Bull 1989; 37(11):3005-9.

25. Duh P-D, Tu Y-Y, Yen G-C. Antioxidant activity of water extract of Harng Jyur (chrysanthemum morifolium ramat). LWT - Food Sci Technol 1999; 32(5):269-77.

26. Martins N, Ferreira ICFR, Barros L, Silva S, Henriques M. Candidiasis: Predisposing Factors, Prevention, Diagnosis and Alternative Treatment Candidiasis: Predisposing Factors, Prevention, Diagnosis. Mycopathologia 2014; 177(5-6):22340.

27. Sulaiman GM, Mohammed WH, Marzoog TR, AlAmiery AA, Kadhum AA, Mohamad AB. Green synthesis, antimicrobial and cytotoxic effects of silver nanoparticles using Eucalyptus chapmaniana leaves extract. Asian Pac J Trop Biomed 2013; 3(1):58-63.

28. Aneja KR, Gupta KK. Studies on the effect of temperature treatment and storage of crude plant extracts on antibacterial activity. Hamdard 
Med 2009; 52(1):185-92.

29. Sehagal R, Arya S, Kumar VL. Inhibitory effect of extracts of latex of Calotropis procera against Candida albicans: A preliminary study XXXVIII Annual Conference of the Indian Pharmacological Society IMAGE Auditorium, Chennai For further information please contact: Indian $\mathrm{J}$ Pharmacol 2005; 37(5):334-5.

30. Pons V, Greenspan D, Lozada-Nur F, McPhail L, Gallant JE, Tunkel A, et al. Oropharyngeal candidiasis in patients with AIDS: Randomized comparison of fluconazole versus nystatin oral suspensions. Clin Infect Dis1997; 24(6):1204-7.

31. Shad AA, Shah HU, Bakht J, Choudhary MI, Ullah J. Nutraceutical potential and bioassay of Apium graveolens L. grown in Khyber Pakhtunkhwa-Pakistan. J Med Plant Res 2011; 5(20):5160-6. 